\title{
The Influence of Heat Treatments on the Porosity of Suspension Plasma-Sprayed Yttria-Stabilized Zirconia Coatings
}

\author{
Johanna Ekberg $^{1} \cdot$ Ashish Ganvir $^{2} \cdot$ Uta Klement $^{1}{ }^{1} \cdot$ Simone $_{\text {Creci }^{3}} \cdot$ \\ Lars Nordstierna ${ }^{3}$
}

Submitted: 6 July 2017 / in revised form: 18 December 2017/Published online: 4 January 2018

(c) The Author(s) 2018. This article is an open access publication

\begin{abstract}
Suspension plasma-sprayed coatings are produced using fine-grained feedstock. This allows to control the porosity and to achieve low thermal conductivity which makes the coatings attractive as topcoats in thermal barrier coatings (TBCs). Used in gas turbine applications, TBCs are exposed to high temperature exhaust gases which lead to microstructure alterations. In order to obtain coatings with optimized thermomechanical properties, microstructure alterations like closing of pores and opening of cracks have to be taken into account. Hence, in this study, TBC topcoats consisting of 4 mol.\% yttria-stabilized zirconia were heat-treated in air at $1150{ }^{\circ} \mathrm{C}$ and thereafter the coating porosity was investigated using image analysis (IA) and nuclear magnetic resonance (NMR) cryoporometry. Both IA and NMR cryoporometry showed that the porosity changed as a result of the heat treatment for all investigated coatings. In fact, both techniques showed that the fine porosity decreased as a result of the heat treatment, while IA also showed an increase in the coarse porosity. When studying the coatings using scanning electron microscopy,
\end{abstract}

This article is an invited paper selected from presentations at the 2017 International Thermal Spray Conference, held June 7-9, 2017, in Düsseldorf, Germany, that has been expanded from the original presentation.

Uta Klement

uta.klement@chalmers.se

1 Department of Industrial and Materials Science, Chalmers University of Technology, 41296 Gothenburg, Sweden

2 Department of Engineering Science, Production Technology Center, University West, 46183 Trollhättan, Sweden

3 Department of Chemistry and Chemical Engineering, Chalmers University of Technology, 41296 Gothenburg, Sweden it was noticed that finer pores and cracks disappeared and larger pores grew slightly and achieved a more distinct shape as the material seemed to become more compact.

Keywords applications, porosity · axial injection · processing $\cdot$ processing, heat treatment $\cdot$ processing, suspension spraying $\cdot$ processing, thermal barrier coatings (TBCs) · properties, nuclear magnetic resonance (NMR) cryoporometry, image analysis (IA)

\section{Introduction}

In order to decrease the greenhouse gas emissions and prolong the lifetime of gas turbines, the demand for a more heat-resistant thermal barrier coating (TBC) topcoat has increased. The topcoats should be characterized by (a) low thermal conductivity to enhance the thermal insulation (b) high strain tolerance regarding cyclic loading to improve lifetime, and (c) a stable microstructure to minimize temperature effects such as phase transformations, grain growth and sintering (Ref 1, 2). Typically, 4 mol.\% yttria-stabilized zirconia (4YSZ) is used as a topcoat material due to its superior properties such as low thermal conductivity, high coefficient of thermal expansion and phase stability up to about $1200{ }^{\circ} \mathrm{C}$ compared to other ceramic materials (Ref 3-5). Conventionally the 4YSZ topcoat is deposited by atmospheric plasma spraying (APS) (Ref 6) or electron beam physical vapor deposition (EBPVD) techniques (Ref 7). APS-sprayed topcoats are known for lower thermal conductivity due to their inherently higher porous nature (Ref 8), whereas the EBPVD topcoats are known for better strain tolerance due to their inherent columnar structure (Ref 9). 
Suspension plasma spraying (SPS) is a relatively new technique compared to APS and EBPVD which has shown to produce topcoats comprising of both high porosity like APS and columnar structures like EBPVD (Ref 10-13). SPS coatings have previously shown good results regarding both lower thermal conductivity due to higher porosity and better strain tolerance due to their columnar structure (Ref 14, 15). Porosity in SPS-sprayed topcoats was found to affect not only the thermal conductivity (Ref 16) and strain tolerance but also the mechanical properties such as hardness and toughness of the TBC (Ref 13). High temperature exposure of such porous columnar topcoats were also found to undergo several microstructural changes such as densification, coarsening and grain growth as reported by Ganvir et al. (Ref 17).

Such microstructural changes at high temperature can degrade the thermal insulation by increasing the thermal conductivity due to reduced phonon scattering interfaces. In yttria-stabilized zirconia (YSZ) coatings, heat transfer takes primarily place by conduction. However, at temperatures above $\sim 1200{ }^{\circ} \mathrm{C}$ also radiation becomes important (Ref 18). The thermal insulation is improved by phonon scattering at inhomogeneities, e.g., grain boundaries, gasfilled pores and vacancies (Ref 19). Porosity contributes to the reduction of thermal conductivity as they are effective scattering sites and the air entrapped in the pores has a lower thermal conductivity than YSZ (Ref 20).

Along with higher porosity, pores in SPS topcoats are found to be distributed over a wider size range (starting form nano-sized pores) and encompass smaller pore sizes compared to conventional, atmospheric plasma-sprayed (APS) coatings (Ref 10, 15, 21). The small pore sizes in SPS TBCs can favor the reduction of thermal conductivity due to the enhanced phonon scattering interfaces (Ref $22,23)$. Such a wide pore size distribution along with the presence of nano-sized pores makes it challenging to characterize and study the evolution of porosity in SPS topcoats. Especially the evolution of very fine pores as pointed out in a recently published sintering work on similar coatings by Ganvir et al. (Ref 17) is difficult due to the unavailability of high-resolution techniques and their role on thermal and mechanical properties. Therefore, such porosity measurement methods should be used which can not only measure the nano-sized fine porosity but also measure the porosity over a complete size range. In this study, NMR cryoporometry is used in combination with image analysis (IA) to analyze the evolution of porosity. An advantage of combining both NMR and IA unlike only IA which was used by Ganvir et al. (Ref 17) is that the complete pore size range distributed at all length scales can be analyzed.

This work was dedicated toward investigating the evolution of porosity during the heat treatment in SPS porous columnar 4YSZ topcoats over a complete pore size range, from few tenths of micrometers down to few nanometers, using the novel technique NMR along with the conventional IA technique.

\section{Experimental}

\section{Coating Production}

The investigated TBCs consist of Hastelloy ${ }^{\circledR} \mathrm{X} X$ substrates $(26 \times 26 \mathrm{~mm})$, CoNiCrAlY bond coats (produced by high velocity air-fuel thermal spray process) and ceramic topcoats. The topcoats were deposited by axial injection SPS using an Axial III high power plasma torch (Northwest Mettech Corp., Vancouver, Canada) equipped with a Nanofeed 350 suspension feed system. Topcoats were produced with a commercial suspension consisting of 4YSZ, having a $25 \mathrm{wt} \%$ of solids dispersed in ethanol (Innovnano, Coimbra, Portugal). The YSZ powder particles have a median particle size of $500 \mathrm{~nm}$ as provided by the supplier. The spray parameters were varied producing three different topcoats (Table 1), here denoted Coating A, Coating B and Coating C.

\section{Heat Treatment}

The TBCs were heat-treated in air at $1150{ }^{\circ} \mathrm{C}$ with a heating rate of $10{ }^{\circ} \mathrm{C} \mathrm{min}^{-1}$. The temperature was chosen to be close to the real temperature in a gas turbine but below the phase transformation temperature of YSZ $\left(1200{ }^{\circ} \mathrm{C}\right)$ (Ref 24). The heat treatments were performed for $50 \mathrm{~h}$ and $200 \mathrm{~h}$, respectively, and the samples were cooled down inside the furnace before removal.

\section{Microstructure and Phase Investigation}

The coatings were analyzed in cross section and top view using a Philips XL-30 scanning electron microscope (SEM) (Philips, Eindhoven, Netherlands) as well as a Zeiss (Leo) 1550 Gemini SEM (Zeiss, Oberkochen, Germany) equipped with a field emission gun. Prior to the SEM investigations, the samples were sectioned using a diamond cutting blade, embedded into epoxy resin using vacuum impregnation technique, polished and gold coated.

Phase analysis was performed using a D8 Advance X-ray Diffractometer (XRD) (Bruker AXS GmbH, Karlsruhe, Germany) with $\mathrm{Cr} \mathrm{K} \alpha$ radiation $(\lambda=2.29 \AA)$. The diffraction angle $(2 \theta)$ was varied between $20^{\circ}$ and $155^{\circ}$ with a step size of 0.05. Match! (Crystal Impact, Bonn, Germany) and TOPAS software (Bruker AXS GmbH, Karlsruhe, Germany) were used for identification of phases and quantitative Rietveld analysis, respectively. 
Table 1 Spray parameters used for producing Coating A, Coating B, and Coating C

\begin{tabular}{|c|c|c|c|c|c|}
\hline & $\begin{array}{l}\text { Spray distance, } \\
\mathrm{mm}\end{array}$ & $\begin{array}{l}\text { Surface speed, } \\
\qquad \mathrm{cm} \mathrm{s}^{-1}\end{array}$ & $\begin{array}{l}\text { Suspension feed } \\
\text { rate, } \mathrm{mL} \mathrm{min}^{-1}\end{array}$ & $\begin{array}{l}\text { Total gas flow } \\
\text { rate, } \mathrm{L} \min ^{-1}\end{array}$ & Plasma gas composition \\
\hline Coating A & 100 & 216 & 45 & 200 & $44 \% \mathrm{Ar}+28 \% \mathrm{H}_{2}+28 \% \mathrm{~N}_{2}$ \\
\hline Coating B & 75 & 146 & 70 & 250 & $44 \% \mathrm{Ar}+28 \% \mathrm{H}_{2}+28 \% \mathrm{~N}_{2}$ \\
\hline Coating C & 100 & 75 & 45 & 300 & $44 \% \mathrm{Ar}+28 \% \mathrm{H}_{2}+28 \% \mathrm{~N}_{2}$ \\
\hline
\end{tabular}

\section{Porosity Measurements Using NMR Cryoporometry}

NMR cryoporometry is a technique which has recently been introduced as a suitable technique for measuring open and connected porosity in TBC topcoats made of YSZ (Ref 25). NMR cryoporometry is capable of measuring pore sizes in the range of a few nanometers up to a micrometer depending on the probe liquid properties and the instrumental hardware (Ref 26). The method relies on the GibbsThomson effect, i.e., that the phase transition temperature in smaller pores is lower than the corresponding bulk temperature (Ref 27-29). Experimentally, a porous material is placed in an NMR vial, saturated with a chosen probe liquid, e.g., water, and cooled down to complete solidification of the probe material. (A probe liquid needs to be used that is wetting the material and not altering the coating microstructure during the measurements.) Afterward, the temperature is slowly increased stepwise and the frozen liquid will start to melt depending on pore size. (Frozen liquid in smaller pore volumes will melt at lower temperature than in larger pore volumes.) Due to the difference in spin-spin relaxation characteristics of the liquidand solid-state probe material, NMR spectroscopy can, by the application of a so-called $T_{2}$-filter, separate the material's liquid phase from its solid content (Ref 30$)$. A variation of signal intensity from the liquid phase with respect to temperature reflects the pore size distribution and since NMR spectroscopy is quantitative, if handled according to a few guidelines, the total porosity for pore sizes below a certain threshold is recorded. Moreover, NMR cryoporometry has also the advantage to provide information regarding the pore shape in the studied material, i.e., the YSZ coatings. Equations 1a and $\mathrm{b}$ are modified GibbsThomson equations that describe the melting and freezing temperature depression, $\Delta T$, of a confined liquid within a pore with radius $r$.

$$
\begin{aligned}
& \Delta T_{\mathrm{m}}=T_{\mathrm{m}}-T_{\text {bulk }}=-G_{1} K /(r-\tau) \\
& \Delta T_{\mathrm{f}}=T_{\mathrm{f}}-T_{\text {bulk }}=-G_{2} K /(r-\tau)
\end{aligned}
$$

where $T_{\mathrm{m}}$ and $T_{\mathrm{f}}$ are the melting and freezing temperatures, respectively, $T_{\text {bulk }}$ is the bulk equilibrium temperature, parameter $K$ is relating to the bulk properties of the probe liquid, the constants $G_{1}$ and $G_{2}$ depend on the geometry of the pores, and $\tau$ is the thickness of the omnipresent liquid layer at the surface (Ref 27). By evaluation of the melting and freezing data, the ratio $\Delta T_{\mathrm{f}} / \Delta T_{\mathrm{m}}$ can be assessed and afterward compared and matched to a corresponding radius, hence providing the geometry.

Prior to the NMR cryoporometry experiments, the coatings were cut into smaller pieces $(3 \times 5 \mathrm{~mm})$ and the YSZ topcoats were detached from the Hastelloy ${ }^{\circledR} \mathrm{X} X$ substrate by dissolving the metallic bond coat in Aqua Regia (nitro-hydrochloric acid). The topcoats were cleaned repeatedly with deionized water and then freeze-dried to remove absorbed liquid from the pores. The topcoat samples were then saturated with probe liquid octamethylcyclotetrasiloxane (OMCTS) during $1 \mathrm{~h}$ centrifugation at $1400 \mathrm{rpm}$. OMCTS was chosen because it completely wets the YSZ, facilitates to investigate a wide pore size range and has previously shown good results when used as probe liquid. All samples were cooled down to a temperature of $-88{ }^{\circ} \mathrm{C}$ for complete solidification before insertion into a Bruker Advance 600 spectrometer (Bruker, Karlsruhe, Germany). For all experiments, the starting temperature was set to $-18{ }^{\circ} \mathrm{C}$ and was increased between each NMR acquisition. In total 54 temperature steps of different values were applied. The NMR integral intensity of the liquid OMCTS signal was recorded at each temperature after sufficiently long time to ensure equilibrium. The bulk density was calculated from the weight of the sample, and the sample dimensions were measured using an optical microscope. For details about the experiments see Ekberg et al. (Ref 25).

\section{Porosity Measurements Using Image Analysis (IA)}

Porosity measurements by IA were taken using ImageJ software, a public domain Java-based image processing program developed at the National Institute of Health, USA. As reported earlier by Ganvir et al. (Ref 31), a multimagnification approach can be adopted to analyze porosity within a wide pore size range. The coatings were thereafter analyzed at three different magnifications: (1) coarse porosity $(>500 \mathrm{~nm})$ at 500 times magnification, (2) fine porosity (500-250 nm) at 7000 times magnification, and (3) very fine porosity $(250-50 \mathrm{~nm})$ at 15,000 times magnification. At each magnification, about 20-25 micrographs were captured using SEM throughout the cross section of 
the polished specimen. The brightness and contrast were normalized using auto-brightness contrast adjustment. An automatic thresholding was applied, and a count mask was used to consider the appropriate pore size range. The procedure was automated in such a way that the software processed all the 20-25 images at once and a mean value was obtained for the total porosity at the respective size range.

\section{Results and Discussion}

The produced coatings have a columnar or feathery columnar structure, which is beneficial with respect to strain tolerance (Fig. 1). Among the investigated topcoats, Coating A appears most porous, while Coatings B and Coating $\mathrm{C}$ seem to have a more dense structure. Coatings $\mathrm{A}$ and Coating $\mathrm{C}$ demonstrated better adherence during heat treatment (only one of the three duplicates showed debonding), while Coating B showed de-bonding in all cases. As can be seen in Fig. 1, a thermally grown oxide (TGO) has formed at the interface between topcoat and bond coat. The TGO is approx. $5 \mu \mathrm{m}$ thick after heat treatment for $50 \mathrm{~h}$ (Fig. 1b, e, and h) and achieved a thickness of about $8 \mu \mathrm{m}$ in the coatings heat treated for $200 \mathrm{~h}$ (Fig. 1c, f, and i). The de-bonding or spallation of the topcoat from the bond coat as mentioned above could be due to the stress build up at the region around TGO due to TGO swelling which could introduce cracks at the topcoat-TGO interface and weakens the adhesion (Ref 32). Such a weak adhesion of the topcoat after heat treatment could be detrimental for the performance of a TBC, especially in case of thermal cyclic fatigue life where the lifetime can be drastically reduced (Ref 32, 33). The detailed investigation regarding the TGO formation and its effect on the coatings performance was not in the scope of this study and is already investigated by others in detail (Ref $32,34,35)$.

\section{Microstructure Investigation}

As can be seen in Fig. 1, through-thickness cracks/column gaps in the YSZ coatings widened during heat treatment. The cracks had a width of 1-3 $\mu \mathrm{m}$ after heat treatment for $50 \mathrm{~h}$, while they opened up to about $10 \mu \mathrm{m}$ after heat treatment for $200 \mathrm{~h}$ in air. Such a widening of column gaps was also noticed earlier in case of EBPVD coatings (Ref 36) as well as in similar SPS coatings (Ref 13, 17, 32). The reason for widening of the column gaps after heat treatment could be due to the difference in the thermal expansion mismatch between the topcoat, bond coat and the substrate (Ref 36). As both MCrAlY bond coat and the Hastelloy ${ }^{\circledR} \mathrm{X}$ substrate have significantly higher coefficient of thermal expansion than the 4YSZ topcoat which may introduce excessive tensile stresses during the heat treatment leading to opening of the column gaps. Another reason could also be the sintering of finer pores (will be discussed later in
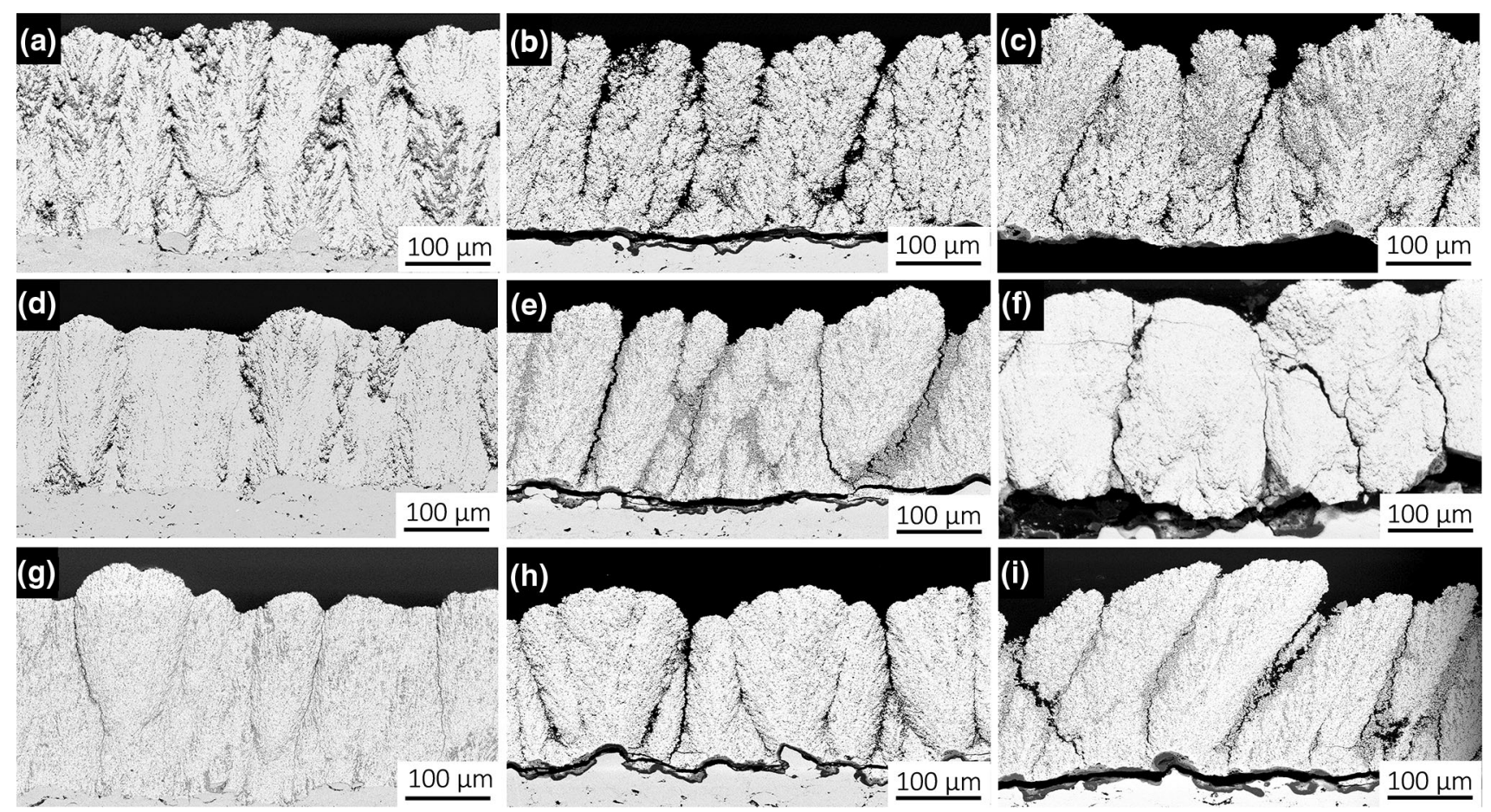

Fig. 1 Cross-sectional micrographs of YSZ coatings in as-sprayed condition, heat treated for $50 \mathrm{~h}$ and heat treated for $200 \mathrm{~h}$, respectively; (a-c) Coating A, (d-f) Coating B and (g-i) Coating C 
"Porosity measurements using image analysis" section). Densification of fine pores due to sintering may assist in opening up of the column gaps because the coating did not show any shrinkage (the dimensions were same before and after heat treatment) as it was constrained by the substrate and bond coat.

In Fig. 2, the SEM micrographs within a column for all the YSZ coatings are shown at higher magnification. As can be seen from the as-sprayed microstructures Fig. 2(a), (d), and ( $\mathrm{g}$ ), the pores are heterogeneously distributed and have a complex shape as well as a wide size distribution in all three coatings. After $50 \mathrm{~h}$ of heat treatment, it can clearly be seen from Fig. 2(b), (e), and (h) that some of the finer cracks have disappeared. Furthermore, it appears as if many of the smaller pores also disappeared and that the larger pores grew slightly in size. These changes can be found to escalate after $200 \mathrm{~h}$ of heat treatment (see Fig. 2c, $\mathrm{f}$, and i). The shape of the larger pores has become more distinct as the material seems to be more compact. The reason for the disappearance of finer cracks and pores after 50 and $200 \mathrm{~h}$ of heat treatment could be due to the sintering as mentioned in the introduction section. Such a densification as well as coarsening of fine cracks/pores and large pores, respectively, was also noticed in case of EBPVD, APS as well as SPS coatings (Ref 17, 37, 38).

Such microstructural changes (widening of column gaps, densification of fine cracks and pores and coarsening of large pores) may influence the coating performance. For instance when the cracks open up, they might cause convective heat flow through the topcoat, which then may increase the thermal conductivity unfavorably. Moreover, on the one hand the densification of finer cracks and pores may increase the thermal conductivity as it can reduce the phonon scattering interfaces (Ref 39), and on the other hand this might be favorable for the mechanical properties, such as increase in the hardness (Ref 40).

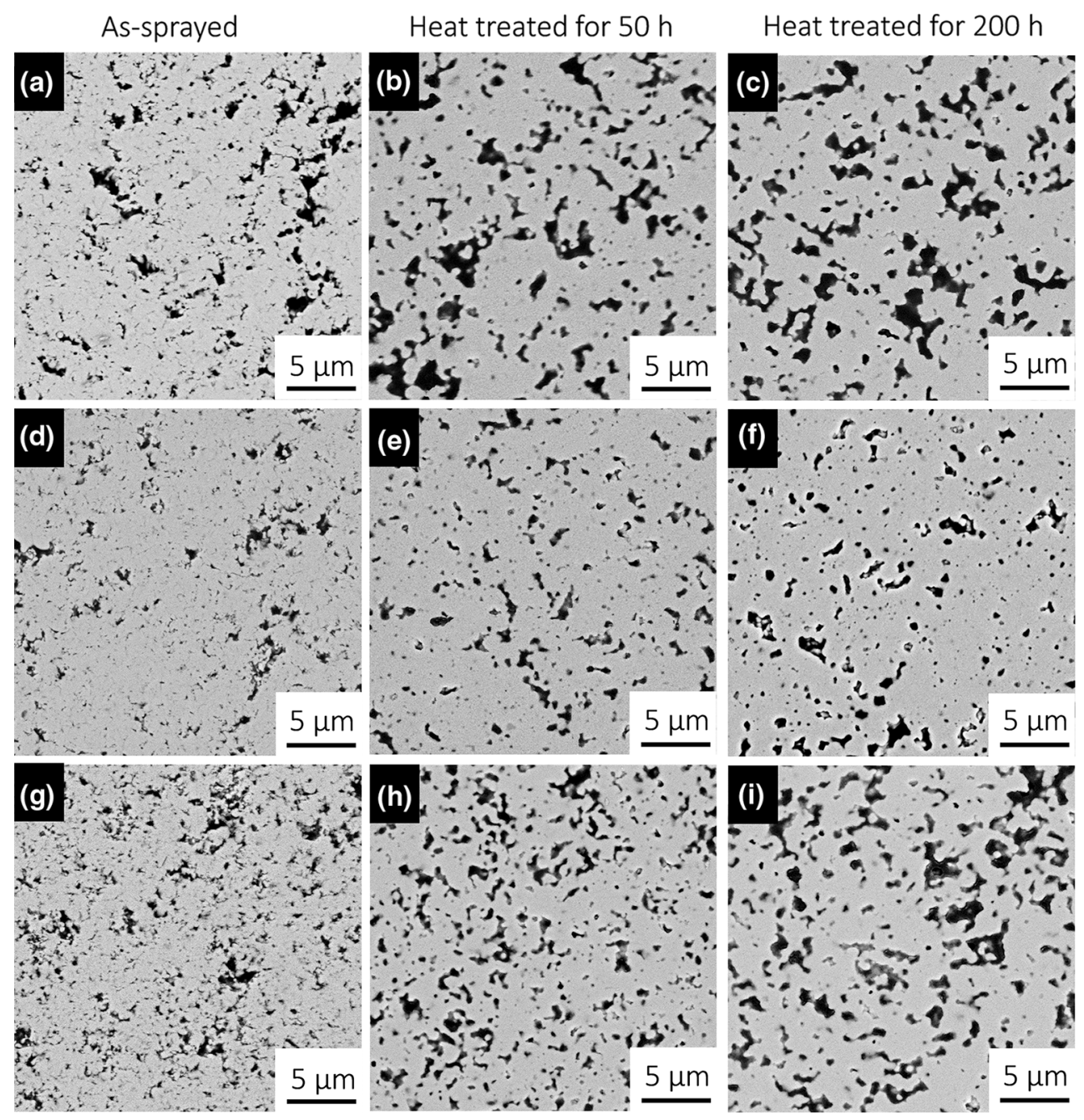

Fig. 2 Cross-sectional micrographs at high magnification within the column in as-sprayed condition, heat treated for $50 \mathrm{~h}$ and heat treated for 200 h, respectively; (a-c) Coating A, (d-f) Coating B and (g-i) Coating C 


\section{XRD for Phase Characterization}

The XRD measurement and Rietveld refinement results revealed that the three coatings consist of non-transformable tetragonal $\left(\mathrm{t}^{\prime}\right)$ zirconia as major phase and some monoclinic zirconia. After heat treatment, the samples show a slight peak broadening (see, e.g., Coating $\mathrm{A}$ in Fig. 3). This peak broadening is not due to phase transformation but likely caused by strains in the crystal lattice. The fractions of monoclinic and tetragonal phases are given in Table 2 . The calculated values are influenced by peak overlap, but it is evident that the phase contents did not change due to heat treatment.

\section{Porosity Measurements Using NMR Cryoporometry}

Pore shape and pore size distribution were investigated using NMR cryoporometry. As seen in the SEM images in Fig. 2, the pore shapes are rather complex. This has also been shown by Klement et al. (Ref 21) using 3D X-ray microscopy. By NMR cryoporometry, the pore shapes were approximated for the three topcoats (Coating A-C). The smaller pores were best described with an elongated pore shape both before and after heat treatment, while the larger pores were rather associated with spherical pore shape. For all three coatings, the change between spherical and elongated pore shape occurred at a pore radius around 150-200 nm.

Pore radii between 5 and $500 \mathrm{~nm}$ were measured in the three different coatings. The measured size range was limited by the instrumental hardware and probe liquid properties. The pore size distribution is presented in Fig. 4 with total volume of pores of a given radius per mass of material $\left(\mathrm{ml} \mathrm{g}^{-1} \mathrm{~nm}^{-1}\right)$ plotted against pore radius $(\mathrm{nm})$. As can be seen, the as-sprayed coatings have a large amount of pores with a radius below $8 \mathrm{~nm}$, around $30 \mathrm{~nm}$

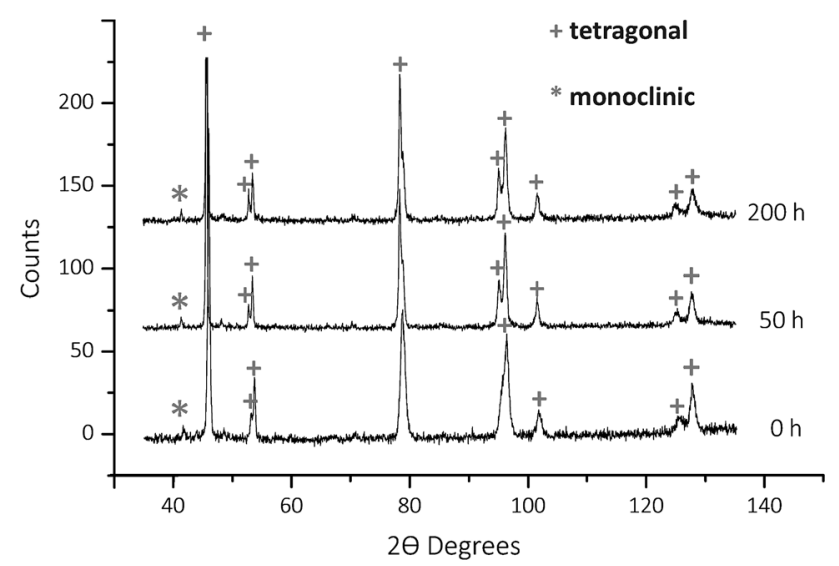

Fig. 3 XRD patterns of Coating A in as-sprayed condition $(0 \mathrm{~h})$ and after heat treatments for 50 and $200 \mathrm{~h}$, respectively and above $80 \mathrm{~nm}$. Moreover, the pore size distributions show that the decrease in porosity during heat treatment of the different coatings is largest for the smallest $(r<50 \mathrm{~nm})$ and largest pores $(r>80 \mathrm{~nm})$. The reduction in number of pores smaller than $50 \mathrm{~nm}$ can be due to sintering, i.e., that small pores and/or cracks closed during the heat treatment or that they grew in size, e.g., by coalescence of pores (Ref 17, 38, 41). Larger pores may also have closed but it is more likely that they grew bigger (e.g., formed through-thickness cracks) (Ref 17, 42) and are beyond the measuring range $(>500 \mathrm{~nm})$. To obtain information about large pores, image analysis has been applied.

By integrating the pore size distribution curves, a quantification of pore volume per gram of material can be achieved. When comparing the three as-sprayed coatings, Coating A has the highest porosity per gram of coating material, followed by Coating $\mathrm{C}$ and Coating $\mathrm{B}$. The porosity values are 12,8 , and $7 \mathrm{vol} . \%$, respectively, as provided in Table 3 . The value of the total porosity encompasses all pores with a radius up to $200 \mathrm{~nm}$. A value of the total porosity which includes the complete pore size range up to $500 \mathrm{~nm}$ pore radius could most possibly be achieved if the sample material is more densely packed in the NMR vial, i.e., when excess of probe liquid (OMCTS) is avoided. The NMR signal intensity of bulk OMCTS is normally negligible as the volume of probe liquid is rather small compared to the volume of sample material. However, in the current investigation of thin YSZ topcoat flakes, the value for the larger pore sizes $(>200 \mathrm{~nm})$ was influenced by the NMR signal intensity from the bulk OMCTS, due to an excess of probe liquid. As a result, Coating $\mathrm{C}$ shows values below zero for some size ranges.

During heat treatment of the coatings, the amount of porosity decreased for all coatings as presented in Fig. 4 and Table 3, respectively. For Coatings $\mathrm{B}$ and $\mathrm{C}$, there is no change in porosity between 50 and $200 \mathrm{~h}$ of heat treatment and the porosity is affected at an early stage of the heat treatment (i.e., closing of pores and opening of cracks). For Coating A on the other hand, the porosity changed from 5 to 8 vol. $\%$ between 50 and $200 \mathrm{~h}$ of heat treatment, which needs to be investigated further. Both Coatings $\mathrm{B}$ and $\mathrm{C}$ have a similar porosity in as-sprayed state. During heat treatment, the porosity decreases more for Coating C, i.e., Coating B demonstrates the smallest change in porosity with a decrease from 7 to 3 vol. $\%$.

\section{Porosity Measurements Using Image Analysis}

When investigating the coatings using image analysis, also the larger pore sizes can be covered and a more complete overview of the porosity achieved. The porosity investigation was carried out by analyzing SEM micrographs of the coatings achieved at three different magnifications, 
Table 2 Rietveld refinement results showing monoclinic and tetragonal zirconia phases present (in wt.\%) in Coating A, B and C before and after heat treatment for 50 and $200 \mathrm{~h}$, respectively

\begin{tabular}{|c|c|c|c|c|c|c|}
\hline & \multicolumn{2}{|c|}{$0 \mathrm{~h}$} & \multicolumn{2}{|c|}{$50 \mathrm{~h}$} & \multicolumn{2}{|c|}{$200 \mathrm{~h}$} \\
\hline & $\begin{array}{l}\text { Monoclinic } \\
\mathrm{ZrO}_{2} \text {, wt. } \%\end{array}$ & $\begin{array}{l}\text { Tetragonal } \\
\mathrm{ZrO}_{2} \text {, wt. } \%\end{array}$ & $\begin{array}{l}\text { Monoclinic } \\
\mathrm{ZrO}_{2} \text {, wt. } \%\end{array}$ & $\begin{array}{l}\text { Tetragonal } \\
\mathrm{ZrO}_{2} \text {, wt. } \%\end{array}$ & $\begin{array}{l}\text { Monoclinic } \\
\mathrm{ZrO}_{2} \text {, wt. } \%\end{array}$ & $\begin{array}{l}\text { Tetragonal } \\
\mathrm{ZrO}_{2} \text {, wt. } \%\end{array}$ \\
\hline Coating A & 2.9 & 97.1 & 2.4 & 97.6 & 2.2 & 97.8 \\
\hline Coating B & 1.9 & 98.1 & 2.9 & 97.1 & $0^{\mathrm{a}}$ & 100 \\
\hline Coating C & 2.8 & 97.2 & 3.7 & 96.3 & 2.1 & 97.9 \\
\hline
\end{tabular}

${ }^{\mathrm{a}} \mathrm{A}$ slight de-bonding of the topcoat for heat-treated Coating B might be the reason for the high noise level in the XRD pattern, which could explain the absence of monoclinic phase
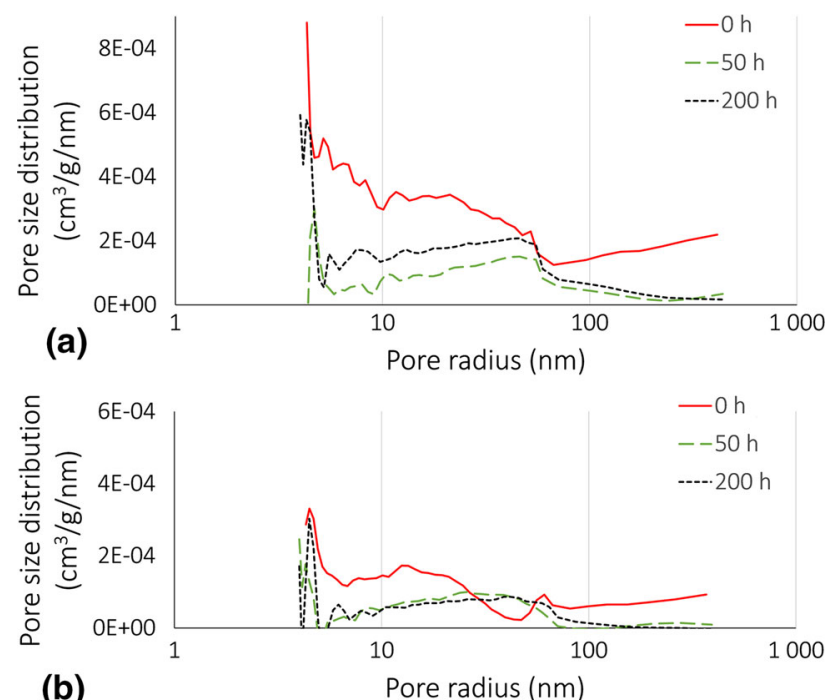

(b)

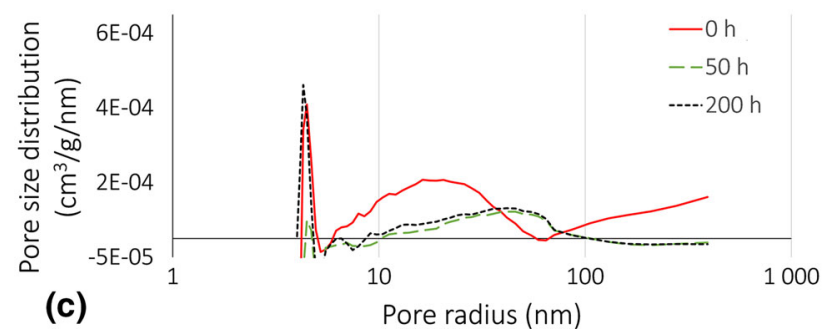

Fig. 4 Pore size distribution in as-sprayed condition and after heat treatment for 50 and $200 \mathrm{~h}$ in (a) Coating A; (b) Coating B and (c) Coating C. Note the log-scale on the $x$-axis

giving the total porosity content at three different pore size intervals (radius), 50-250, 250-500, and $>500 \mathrm{~nm}$, see Fig. 5. The results are plotted in Fig. 6(a), (b), and (c), respectively, with porosity in area percentage against time of heat treatment. In Fig. 6(d) the porosity content for the three intervals is summarized into a total porosity over the whole size range from micron down to nanometer size, and these values are listed in Table 4 . The porosity values for the as-sprayed samples are similar to each other (22-23 vol.\%), while the porosities for the heat-treated samples are varying from 15 to 39 vol.\%.
Table 3 Total porosity measured by NMR cryoporometry in vol.\% for pore radii between 5 and $200 \mathrm{~nm}$ in the as-sprayed and heattreated topcoats

\begin{tabular}{lccc}
\hline & $0 \mathrm{~h}$, vol. $\%$ & $50 \mathrm{~h}$, vol. $\%$ & $200 \mathrm{~h}$, vol. $\%$ \\
\hline Coating A & 12 & 5 & 8 \\
Coating B & 7 & 3 & 3 \\
Coating C & 8 & 1 & 1 \\
\hline
\end{tabular}

To better understand the change in porosity during heat treatment, the intervals are investigated separately. Figure 6(a) shows a decrease in porosity in all three coatings for pores in the size range of $50-250 \mathrm{~nm}$. A similar behavior has been seen in the NMR cryoporometry measurements in Fig. 4. In addition, Table 3, where the porosity for pores in the size range $5-200 \mathrm{~nm}$ is reported, also shows a decrease in the porosity for all three coatings after heat treatment. However, the absolute numbers reported in Table 3 for porosity measured by NMR and shown in Fig. 5 and 6(a) measured by IA do not correspond to each other. This is because of the different size range considered in Table $3(5-200 \mathrm{~nm})$ and in Fig. 5 and 6(a) (50-200 nm). It is difficult to measure very fine pores up to few nanometers by image analysis procedure adopted in this work as the highest magnification used may not be sufficient to consider fine pores. This could be solved by using a four-magnification approach unlike three-magnification approach suggested in this work, where even higher magnification than 15,000 times can be used; however, this would be a more time-consuming process. This is where techniques like NMR can come into picture which can easily access pores up to few nanometers. Another possible reason for the difference in the porosity values measured by NMR and IA could be because NMR can only access open and connected porosity, whereas IA can measure even closed porosity. However, neither NMR nor IA could distinguish between the open and closed porosity which is possible by a technique called X-ray microscopy (XRM) (Ref 21). The decrease in such fine pores $(<250 \mathrm{~nm})$ as 


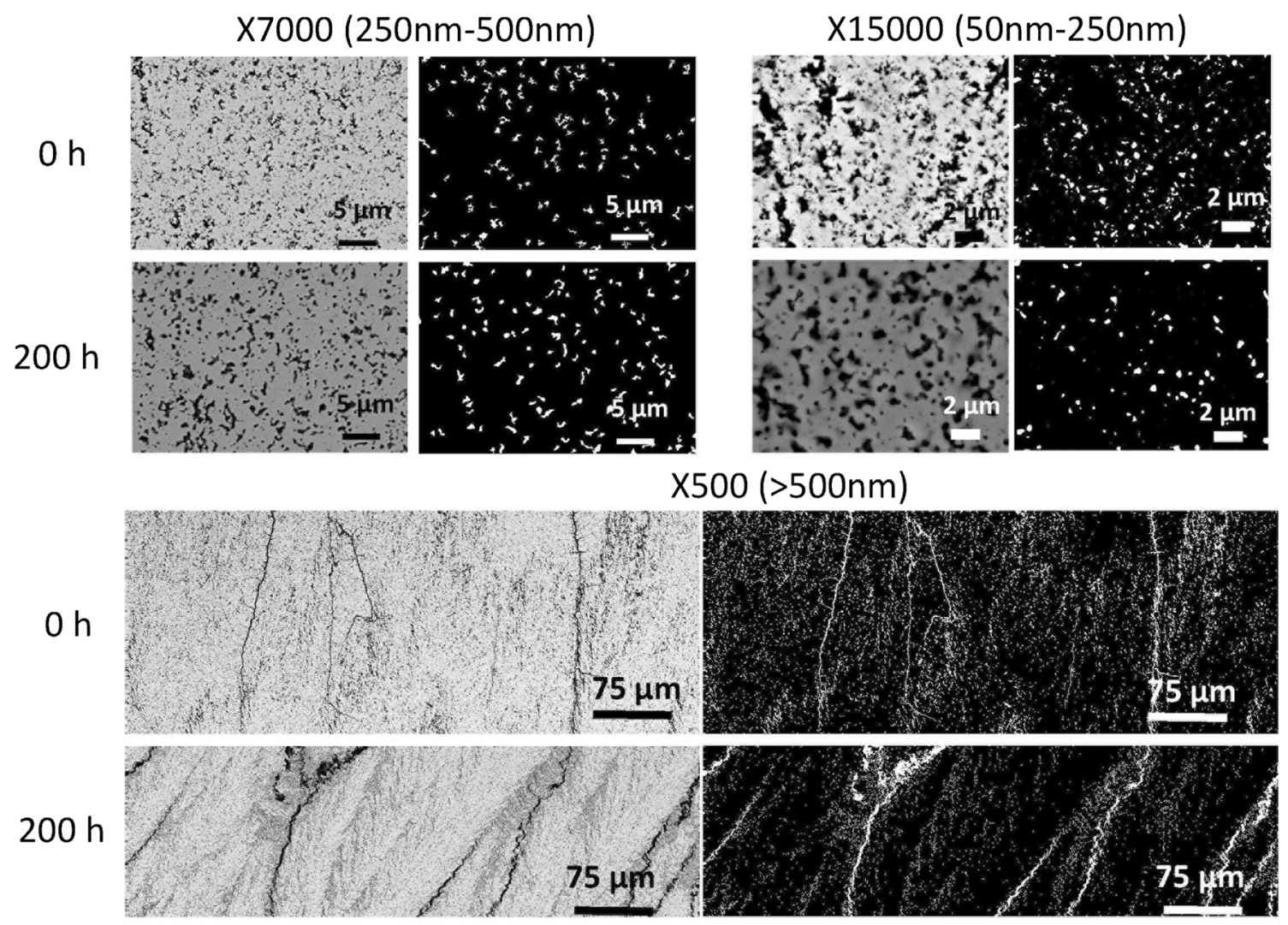

Fig. 5 SEM micrographs of Coating $\mathrm{C}$ and the corresponding filtered binary images (only showing the pores in the respective size range at three different magnifications, i.e., 500, 7000 and 15,000 times), showing the change in porosity after $200 \mathrm{~h}$ of heat treatment

confirmed by both IA and NMR could be due to sintering of the small pores and cracks.

For pores in the size range of $250-500 \mathrm{~nm}$, image analysis shows a slight increase in porosity content during heat treatment, see Fig. 5 and 6(b). This could be due to the coalescence of adjacent fine pores and/or pore rearrangement which can be noticed in Fig. 2(b, e, and h) or (c, f and i). The SEM micrograph clearly shows the fine pores grouped together which proves the coalescence, and the particular shape of pores proves the pore rearrangement. As it can be seen in Fig. 1, the heat-treated topcoats show the presence of a TGO layer between the bond coat and the topcoat. The growth of the TGO during heat treatment could lead to crack formation and hence result in coating failure (Ref 33). As can be noticed in Fig. 5, IA results for pore sizes above $500 \mathrm{~nm}$ are influenced by cracks in the coatings. That could be the reason why Coatings A-C do not show a consistent behavior for pores above $500 \mathrm{~nm}$ in size (Fig. 6c).

As can be seen in the graphs in Fig. 6, the curves for larger pore sizes (Fig. 6c) resemble the curves for the total porosity (Fig. 6d), which indicates that the larger pores dominate the total porosity. Furthermore, the decrease/increase in porosity is flattening out between 50 and $200 \mathrm{~h}$ of heat treatment (Fig. $6 a$ and b), a similar pattern as seen in the NMR cryoporometry measurements. This suggests that there were no significant microstructural changes occurring after $50 \mathrm{~h}$. Hence, both NMR cryoporometry and IA indicate that the major change in porosity during heat treatment is occurring at an early stage, i.e., at less than $50 \mathrm{~h}$ of heat treatment. (Shorter annealing treatments are planned in future.) The reason why this is not seen in the curves for the larger pore size range (Fig. 6c) is most probably due to oxide growth and widening of the through-thickness cracks.

\section{Summary and Conclusions}

The SPS-sprayed YSZ coatings were investigated using both NMR cryoporometry and IA to cover a wide pore size range. NMR cryoporometry investigations on SPS YSZ coatings provided porosity, pore size distribution as well as an assessment of pore shape for pores with radii between 5 and $500 \mathrm{~nm}$. In comparison, IA provided information about the total porosity for all pores with a radius above $50 \mathrm{~nm}$. When using NMR cryoporometry, the comparison between the as-sprayed and heat-treated coatings showed that the porosity decreased during heat treatment for all investigated coatings. In connection with the heat treatments, the 

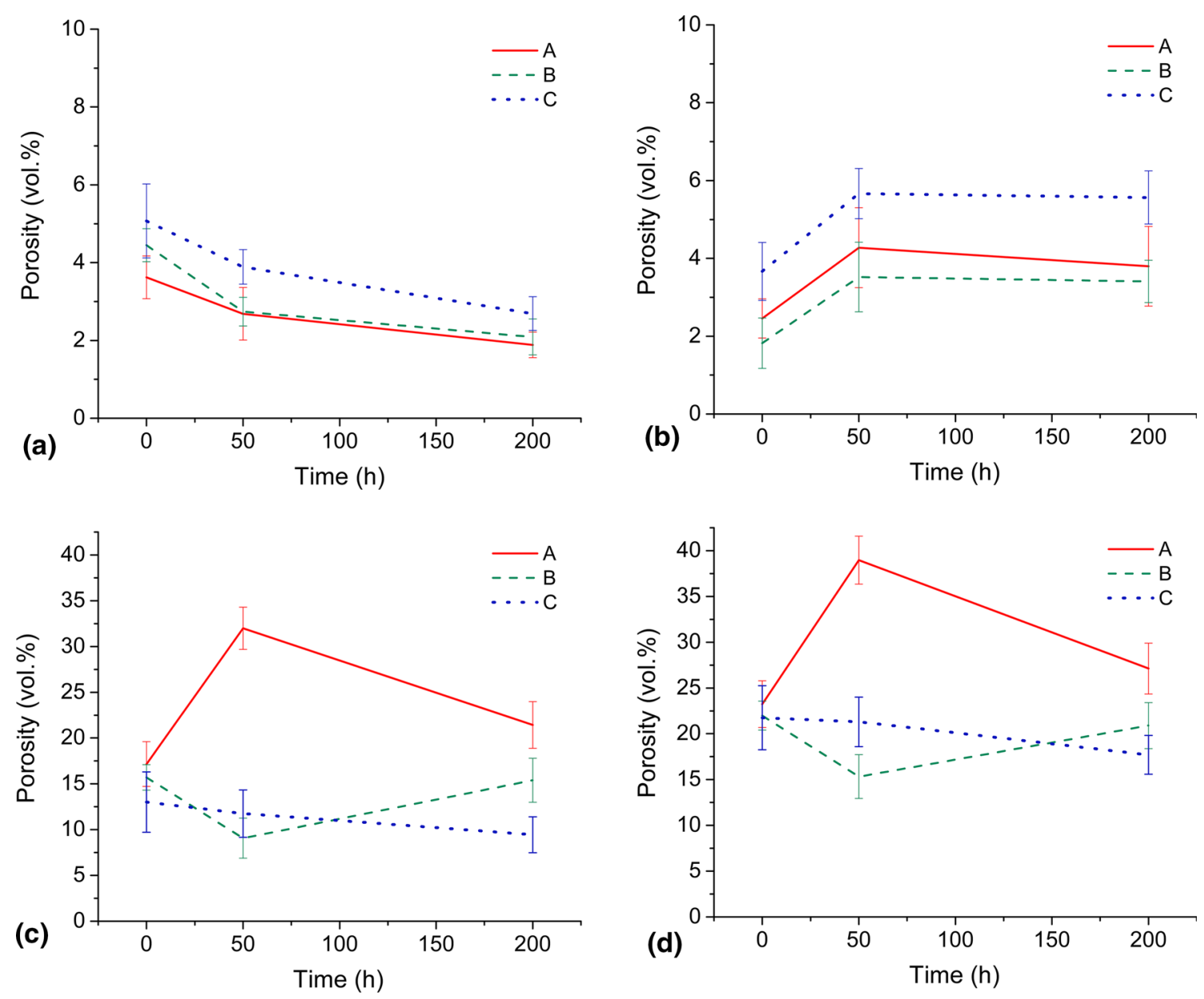

Fig. 6 Total porosity (area\%) against heat treatment duration time measured by image analysis for Coating A-C for (a) pore radii between 50 and $250 \mathrm{~nm}$; (b) pore radii between 250 and $500 \mathrm{~nm}$; (c) pore radii $>500 \mathrm{~nm}$ and (d) all pores with a radius above $50 \mathrm{~nm}$

Table 4 Total porosity measured by image analysis in area\% for the as-sprayed and heat-treated topcoats

\begin{tabular}{lccc}
\hline & $0 \mathrm{~h}$, area\% & $50 \mathrm{~h}$, area\% & $200 \mathrm{~h}$, area $\%$ \\
\hline Coating A & $23 \pm 2.5$ & $39 \pm 2.6$ & $27 \pm 2.9$ \\
Coating B & $22 \pm 1.6$ & $15 \pm 2.4$ & $21 \pm 2.5$ \\
Coating C & $22 \pm 3.5$ & $21 \pm 2.7$ & $18 \pm 2.1$ \\
\hline
\end{tabular}

number of pores with a radius below $50 \mathrm{~nm}$ and above $80 \mathrm{~nm}$, respectively, decreased. The reduction in the smaller pore sizes can be due to sintering effects on finer cracks and nanopores, i.e., that small pores and/or cracks closed. Alternatively, they could also have grown in size, e.g., by coalescence of pores. The reduction in the number of large pores is likely caused by growth/coalescence of the pores and achieving a radius that is beyond the measured range for NMR cryoporometry $(>500 \mathrm{~nm})$. For the three topcoats, the assessable pore shape information indicates that the smaller pores are of elongated shape, while the larger pores $(>150-200 \mathrm{~nm})$ are more confined and spherical.

IA has complemented the NMR results, and in addition to showing a decrease in the amount of pores between 50 and $250 \mathrm{~nm}$, it showed an increase in porosity for pore sizes between 250 and $500 \mathrm{~nm}$, which is believed to be due to the coalescence of fine pores and/or pore rearrangement. The change in porosity for large pores $(>500 \mathrm{~nm})$ due to heat treatment was most likely found to be influenced by the TGO growth and crack formation, along with widening of the inter-columnar spacing. Overall, both NMR and IA techniques are needed to fully understand the sintering effect over the complete pore size range.

Failure of the TBCs is likely to occur in connection with the growth of the TGO, causing de-bonding and spallation of the topcoats. For all investigated coatings, the TGO grew to a thickness of $8 \mu \mathrm{m}$ after $200 \mathrm{~h}$ of heat treatment. (In as-sprayed state the thickness was negligible.) Debonding of the topcoat occurred for one of the coatings (Coating B) after $200 \mathrm{~h}$ of heat treatment. 
Acknowledgments The authors would like to thank Monica Vilemova, IPP Prague, Czech Republic, for assistance with XRD analysis. The NMR cryoporometry measurements were taken at the Swedish NMR Centre, Göteborg, Sweden. Västra Götalandsregionen is acknowledged for financial support of this work in connection with the PROSAM project.

Open Access This article is distributed under the terms of the Creative Commons Attribution 4.0 International License (http://crea tivecommons.org/licenses/by/4.0/), which permits unrestricted use, distribution, and reproduction in any medium, provided you give appropriate credit to the original author(s) and the source, provide a link to the Creative Commons license, and indicate if changes were made.

\section{References}

1. R.A. Miller, Current Status of Thermal Barrier Coatings-An Overview, Surf. Coat. Technol., 1987, 30(1), p 1-11

2. R.A. Miller, Thermal Barrier Coatings for Aircraft Engines: History and Directions, J. Therm. Spray Technol., 1997, 6(1), p 35-42

3. N.P. Padture, M. Gell, and E.H. Jordan, Thermal Barrier Coatings for Gas-Turbine Engine Applications, Science, 2002, 296(5566), p 280-284

4. S. Stecura, Optimization of the NiCrAl-Y/ZrO2-Y2O3 Thermal Barrier System, 1985, p. NASA-TM-86905

5. R. Vassen, A. Stuke, and D. Stover, Recent Developments in the Field of Thermal Barrier Coatings, J. Therm. Spray Technol., 2009, 18(2), p 181-186

6. N. Curry, N. Markocsan, X.-H. Li, A. Tricoire, and M. Dorfman, Next Generation Thermal Barrier Coatings for the Gas Turbine Industry, J. Therm. Spray Technol., 2011, 20(1-2), p 108-115

7. R. Naraparaju, M. Hüttermann, U. Schulz, and P. Mechnich, Tailoring the EB-PVD Columnar Microstructure to Mitigate the Infiltration of CMAS in 7YSZ Thermal Barrier Coatings, J. Eur. Ceram. Soc., 2017, 37(1), p 261-270

8. N. Curry and J. Donoghue, Evolution of Thermal Conductivity of Dysprosia Stabilised Thermal Barrier Coating Systems During Heat Treatment, Surf. Coat. Technol., 2012, 209, p 38-43

9. R.W. Steinbrech, V. Postolenko, J. Monch, J. Malzbender, and L. Singheiser, Testing Method to Assess Lifetime of EB-PVD Thermal Barrier Coatings on Tubular Specimens in Static and Cyclic Oxidation Tests, Ceram. Int., 2011, 37(1), p 363-368

10. A. Ganvir, N. Curry, N. Markocsan, P. Nylén, S. Joshi, M. Vilemova, and Z. Pala, Influence of Microstructure on Thermal Properties of Axial Suspension Plasma-Sprayed YSZ Thermal Barrier Coatings, J. Therm. Spray Technol., 2016, 25(1-2), p 202212

11. P. Sokolowski, S. Kozerski, L. Pawlowski, and A. Ambroziak, The Key Process Parameters Influencing Formation of Columnar Microstructure in Suspension Plasma Sprayed Zirconia Coatings, Surf. Coat. Technol., 2014, 260, p 97-106

12. B. Bernard, L. Bianchi, A. Malie, A. Joulia, and B. Remy, Columnar Suspension plasma Sprayed Coating Microstructural Control for Thermal Barrier Coating Application, J. Eur. Ceram. Soc., 2016, 36(4), p 1081-1089

13. D. Zhou, O. Guillon, and R. Vassen, Development of YSZ Thermal Barrier Coatings Using Axial Suspension Plasma Spraying, Coatings, 2017, 7(8), p 120

14. I.O. Golosnoy, A. Cipitria, and T.W. Clyne, Heat Transfer Through Plasma-Sprayed Thermal Barrier Coatings in Gas Turbines: A Review of Recent Work, J. Therm. Spray Technol., 2009, 18(5-6), p 809-821
15. A. Bacciochini, G. Montavon, J. Ilavsky, A. Denoirjean, and P. Fauchais, Porous Architecture of SPS Thick YSZ Coatings Structured at the Nanometer Scale $(\sim 50 \mathrm{~nm})$, J. Therm. Spray Technol., 2010, 19(1-2), p 198-206

16. N.P. Padture, M. Gell, and E.H. Jordan, Thermal Barrier Coatings for Gas-Turbine Engine Applications, Science, 2002, 296(5566), p 280-284

17. A. Ganvir, N. Markocsan, and S. Joshi, Influence of Isothermal Heat Treatment on Porosity and Crystallite Size in Axial Suspension Plasma Sprayed Thermal Barrier Coatings for Gas Turbine Applications, Coatings, 2016, 7(1), p 4

18. I.O. Golosnoy, A. Cipitria, and T.W. Clyne, Heat transfer Through Plasma-Sprayed Thermal Barrier Coatings in Gas Turbines: A Review Of Recent Work, J. Therm. Spray Technol., 2009, 18(5-6), p 809-821

19. E.C. Subbarao, Advanced Ceramics-An Overview, Sadhana, 1988, 13(1-2), p 1-11

20. D. Kassner, H. Stuke, A. Rödig, M. Vassen, and R. Stover, Influence of Porosity on Thermal Conductivity and Sintering in Suspension Plasma Sprayed Thermal Barrier Coatings, Adv. Ceram. Coat. Interfaces III, Ceram. Eng. Sci. Proc., 2008, 29(4), p $147-158$

21. U. Klement, J. Ekberg, and S.T. Kelly, 3D Analysis of Porosity in a Ceramic Coating Using X-ray Microscopy I SpringerLink, $J$ Therm Spray Tech, 2017, 26, p 456-463

22. H.S. Yang, G.R. Bai, L.J. Thompson, and J.A. Eastman, Interfacial Thermal Resistance in Nanocrystalline Yttria-Stabilized Zirconia, Acta Mater., 2002, 50(9), p 2309-2317

23. A.M. Limarga, S. Shian, M. Baram, and D.R. Clarke, Effect of High-Temperature Aging on the Thermal Conductivity of Nanocrystalline Tetragonal Yttria-Stabilized Zirconia, Acta Mater., 2012, 60(15), p 5417-5424

24. C. Viazzi, J.-P. Bonino, F. Ansart, and A. Barnabé, Structural Study of Metastable Tetragonal YSZ Powders Produced Via a Sol-Gel Route, J. Alloys Compd., 2008, 452(2), p 377-383

25. J. Ekberg, L. Nordstierna, and U. Klement, Porosity Investigation of Thermal Barrier Coatings Using NMR Cryoporometry, Surf. Coat. Technol., 2017, 315, p 468-474

26. J. Mitchell, J.B.W. Webber, and J.H. Strange, Nuclear Magnetic Resonance Cryoporometry, Phys. Rep., 2008, 461(1), p 1-36

27. C. Boissier, F. Feidt, and L. Nordstierna, Study of Pharmaceutical Coatings by Means of NMR Cryoporometry and SEM Image Analysis, J. Pharm. Sci., 2012, 101(7), p 2512-2522

28. J. Strange, M. Rahman, and E. Smith, Characterization of Porous Solids by NMR, Phys. Rev. Lett., 1993, 71(21), p 3589-3591

29. J.H. Strange, J.B.W. Webber, and S.D. Schmidt, Pore size Distribution Mapping, Magn. Reson. Imaging, 1996, 14(7-8), p 803-805

30. G.M. Lampman, D.L. Pavia, G.S. Kriz, and J.R. Vyvyan, Spectroscopy, 4th ed., Brooks/Cole, Pacific Grove, 2010

31. A. Ganvir, N. Curry, S. Björklund, N. Markocsan, and P. Nylén, Characterization of Microstructure and Thermal Properties of YSZ Coatings Obtained by Axial Suspension Plasma Spraying (ASPS), J. Therm. Spray Technol., 2015, 24(7), p 1195-1204

32. M. Gupta, N. Markocsan, X.-H. Li, and R.L. Peng, Improving the Lifetime of Suspension Plasma Sprayed Thermal Barrier Coatings, Surf. Coat. Technol., 2017, 332, p 550-559

33. A. Rabiei and A.G. Evans, Failure Mechanisms Associated with the Thermally Grown Oxide in Plasma-Sprayed Thermal Barrier Coatings, Acta Mater., 2000, 48(15), p 3963-3976

34. W.R. Chen, X. Wu, B.R. Marple, D.R. Nagy, and P.C. Patnaik, TGO Growth Behaviour in TBCs with APS and HVOF Bond Coats, Surf. Coat. Technol., 2008, 202(12), p 2677-2683

35. A. Rabiei and A.G. Evans, Failure Mechanisms Associated with the Thermally Grown Oxide in Plasma-Sprayed Thermal Barrier Coatings, Acta Mater., 2000, 48(15), p 3963-3976 
36. V. Lughi, V.K. Tolpygo, and D.R. Clarke, Microstructural Aspects of the Sintering of Thermal Barrier Coatings, Mater. Sci. Eng., A, 2004, 368(1-2), p 212-221

37. R. Krishnamurthy and D.J. Srolovitz, Sintering and Microstructure Evolution in Columnar Thermal Barrier Coatings, Acta Mater., 2009, 57(4), p 1035-1048

38. N. Curry, W. Janikowski, Z. Pala, M. Vilemova, and N. Markocsan, Impact of Impurity Content on the Sintering Resistance and Phase Stability of Dysprosia- and Yttria-Stabilized Zirconia Thermal Barrier Coatings, J. Therm. Spray Technol., 2014, 23(1-2), p 160-169

39. R.B. Dinwiddie, S.C. Beecher, W.D. Porter, and B.A. Nagaraj, The Effect of Thermal Aging on the Thermal Conductivity of
Plasma Sprayed and EB-PVD Thermal Barrier Coatings, p. V005T13A006, 1996.

40. C.C. Li, T. Wang, X.J. Liu, Z.H. Zheng, and Q. Li, Evolution of Mechanical Properties of Thermal Barrier Coatings Subjected to Thermal Exposure by Instrumented Indentation Testing, Ceram. Int., 2016, 42(8), p 10242-10250

41. H. Kassner, A. Stuke, M. Rodig, R. Vassen, and D. Stover, Influence of Porosity on Thermal Conductivity and Sintering in Suspension Plasma Sprayed Thermal Barrier Coatings, Adv. Ceram. Coat. Interfaces III, Ceram. Eng. Sci. Proc, 2009, 46, p 147

42. H.E. Exner and C. Müller, Particle Rearrangement and Pore Space Coarsening During Solid-State Sintering, J. Am. Ceram. Soc., 2009, 92(7), p 1384-1390 